https://doi.org/10.48009/1_iis_2014_353-359

Issues in Information Systems

Volume 15, Issue I, pp. 353-359, 2014

\title{
A CASE FOR THE SOCIAL ENTERPRISE COMMUNITY TO BUILD A DATAWAREHOUSE AND ADOPT BI TOOLS
}

\author{
Catherine A. Lada, Robert Morris University, calst24@mail.rmu.edu \\ Keiona L. Middleton, Robert Morris University, klmst920@mail.rmu.edu
}

\begin{abstract}
Associations of social entrepreneurs, funders, academics, nonprofit organizations, government agencies, all have vast bodies of knowledge related to social issues such as poverty, homelessness, hunger-and how these organizations are having an impact on reducing them. The knowledge exists in multiple forms - video, audio, white papers, case studies, etc. The largest social enterprises have online repositories of these materials in databases such as MySQL. What is missing is a database connection between these stakeholders (which can be considered communities of practice involved in solving social issues), and business intelligence tools, to allow practitioners from across the world access these various repositories of knowledge, information, and data. We propose that social entrepreneurship associations form a knowledge coalition/partnership to explore the benefits and logistics of cocreating a data warehouse for the benefit of the world-wide community of practice.
\end{abstract}

Keywords: Digital Library, Business Intelligence, Data Warehouse, Social Entrepreneur, Social Return on Investment, National Digital Science Library

\section{INTRODUCTION}

This review of the literature of social entrepreneurship, social return on investment, data warehouses, business intelligence tools, and digital libraries includes the case of the National Science Foundation-funded National Science Digital Library (NSDL). The NSDL is a potential model for informing the creation of a similar DL for the SE community of practice.

\section{Social Entrepreneurship}

Though there is no consensus definition, many scholars agree the elements of this definition are representative of the variety of definitions of social entrepreneurs [SE]. [3, 6, 8, 9] Social entrepreneurs "create social value through innovation and leveraging financial resources, regardless of source, for social, economic, and community development." [18] Perhaps the most important differentiator between commercial and social enterprises is the ultimate purpose of the enterprise. Social enterprises seek a "double bottom line," that is, both financial and social returns (such as reducing poverty). The profits are used to expand the enterprise and create more social impact, rather than creating personal wealth. "The fundamental purpose of social entrepreneurship is creating social value for the public good, whereas commercial entrepreneurship aims at creating profitable operations resulting in private gain" $[3,6,8,9]$.

Well-known social entrepreneurs include Wendy Kopp (Teach for America) Bill Drayton (Ashoka), Bill Strickland (Manchester Bidwell Corporation), and Muhammad Yunus (Grameen Bank). Yunus is the Bangladeshi businessman who won the 2006 Nobel Peace Prize for creating the Grameen bank in 1983. "Lasting peace cannot be achieved unless large population groups find ways in which to break out of poverty. Micro-credit is one such means. Development from below also serves to advance democracy and human rights" (nobelprize.org, The Nobel Peace Prize for 2006, para. 1).

Yunus' social enterprise pioneered a completely different banking business model, thus disrupting the banking industry while at the same time lifting millions out of poverty by making "micro-loans" to the rural poor of his country. [24] The bank has loaned US \$6 billion to-date with a 99 percent repayment rate and the bank routinely 
makes a profit. [24] Financially, it is self-reliant and has not taken donor money since 1995." Further, "Sixty four percent of our borrowers who have been with the bank for five years or more have crossed the poverty line." [24]

Social enterprises, like their more traditional commercial counterparts, operate within an "ecosystem" of stakeholders. $[10,23]$ However, the ecosystem is much more complex and inherently visible in shaping the work and even the impact of the social enterprise than it is for traditional commercial enterprises. $[10,23]$ In fact, the importance of the ecosystem is not only that it shapes the social enterprise and those within it, it shapes how social problems are solved, by whom, and in what ways. Solving social problems requires that the ecosystem, or "context" of the social problem are central to the discussion. $[7,10,15,23]$ That ecosystem includes geographic, political, economic, cultural, institutional, historical, and economic factors. [7, 10, 15, 23]

\section{Social Return on Investment}

As mentioned earlier, seeking both financial gain and a positive impact on social issues is what differentiates a commercial from a social enterprise. There are numerous tools - profit and loss statements, financial reporting, costbenefit analyses, budgets, generally accepted accounting principles (GAAP), etc. - that allow both types of enterprises reliably and accurately monitor financial performance. [12] These mature tools provide a common basis for apples-to-apples comparisons of financial performance between companies. [12]

There are no commonly used tools in the SE community of practice that are employed to measure "social return on investment," or SROI. [12, 23] SROI seeks to evaluate social impact and social outcome data through the lens of cost. [12] "Without a definition of our purpose-of what we mean by a 'good result' or by 'good performance'—we cannot create management processes that will systematically generate and improve results over time." [23] Second, in the case of social enterprises in particular, but also any corporation or entity working to solve social problems, transparency and accountability principles demand that some effort is made to measure the impact of the enterprise activities. [6, 7, 10, 14, 21]

Collaborations among the various stakeholders involved in the social entrepreneur's ecosystem to create long-term systemic change are necessary to achieve that change. [12] Vast amounts of data are needed and used. Some of it organizational: financial, human resources, management, marketing; $[10,15,19,23]$ some of it about the issue(s) the SE is trying to solve - statistics on poverty, homeless, and more. $[6,8,12,14]$ The SE Toolbelt mentioned below is one tiny repository of the knowledge and tools built up in association databases. There is also a growing body of academic data and studies about what interventions work better than others (such whether the meals on wheels program worked better than offering free school breakfasts in lessening the hungry in an area). None of this valuable information, data, and knowledge is easily accessible, and not organized in a way that social entrepreneurs, their funders, or government agencies can make sound decisions based on actual data.

\section{Data Warehousing and Business Intelligence}

An important part of the social entrepreneur's ecosystem are the associations to which the various stakeholders belong - associations including Ashoka, Acumen, the Social Enterprise Alliance, the Global Impact Investing Network, and more. These associations have repositories of valuable information online, including best practices, case studies, how-to guides, and more. Some of the repositories are open-access, such as the SE Toolbelt, shown in Figure 1 below, offered by the Social Enterprise Alliance. This repository contains actual content as well as metadata pointing to content stored in other databases. It does not have the capabilities to include business intelligence tools, and is indeed a relational database. 


\section{setoolbelt \\ work outside the box}

Learn | Find | Share | Collaborate

Pick a category to launch a search.

Browse by Resource Type

$\square$ toolkit/manual (387)

$\square$ tips/guidelines (349)

research/study (236)
Browse by Topics

$\square$ Background Information (266)

$\square$ Resource Mobilization (262)

$\square$ strategic Planning (237)

Figure 1: The SE Toolbelt, http://www.setoolbelt.org/

A database like the SE Toolbelt acts as a centralized repository for storing an organization's data. A data warehouse on the other hand, would combine data from multiple, usually varied sources, into one comprehensive and easily manipulated denormalized database that is then used by an organization or groups of organizations or individuals to access this data for a wide range of purposes [22]. A data warehouse is a relational or multidimensional database designed for query and analysis rather than for transaction processing. It usually contains historical data derived from transaction data, but it can include data from other sources. It separates analysis workload from transaction workload and enables an organization to consolidate data from several sources [22].

Data warehouses provide organizations with multiple benefits for information sharing, collaboration and in-depth data analysis. One of the greatest benefits of a data warehouse is the ability to allow users to quickly access accurate data across the enterprise. This kind of quick accessibility allows individuals to gain a holistic view of an organization, immediately providing an opportunity for collaboration and feedback among or across multiple organizations. Another great advantage of a data warehouse is that it can store huge amounts of historical data, enabling advanced analysis of different time periods and trends, which allow future predictions.

The ability for organizations to perform advance data analysis on vast amounts of historical data sets, are made possible through Business Intelligence (BI) tools. "Business Intelligence is a set of methodologies, processes, architectures, and technologies that transform raw data into meaningful and useful information used to enable more effective strategic, tactical, and operational insights and decision-making." [22]

Social enterprises, just like any other enterprise, need to manage growth strategically, and establish clear outcomes, or the results will be poor-or dire. "Poorly managed growth can detract from an organization's ability to create greater social impact over the long term, or, worse, can even threaten the viability of the social enterprise itself." [23]

BI tools make analyzing, reporting, and managing financial data more convenient. Input and outputs can be tracked with greater efficiency. Likewise, BI tools can also be used to monitor Key Performance Indicators (KPI), real-time, without the latency of quarterly or monthly reports. [4] The time typically spent running and refining reports can be reduced with the utilization of dashboards, which can provide immediate and precise visibility into the day-to-day operations of the organization. This insight can improve productivity and boost profit margins. [4] And, in the case of social enterprises, provide insights as to which resources generated the most return on investment (ROI) for programs designed to solve or mitigate social issues such as poverty. 
The various BI tools include Online Analytical Processing (OLAP), Corporate Performance Management (CPM), and Enterprise Reporting Systems. OLAP tools enable organizations to make tactical business decisions and are used to extract business information by organizing the data into dimensions such as product, sales territory, customers and sales period. Users can devise queries to find out, for example, whether particular products are selling poorly in certain areas [22].

OLAP tools allow users to rotate their views on data, changing the relationships in order to get more detailed insight into corporate trends and identify potential issues and opportunities ("OLAP Tools - Online Analytic Processing Information Builders," n.d.). OLAP technology has been incorporated into business intelligence software such as those from Cognos and Business Objects. The use of Corporate Performance Management tools enables strategiclevel business decisions to be performed. CPM tools provide digital scorecards for highly visual metrics. Scorecards utilize cubes, queries or spreadsheets as data sources, which provides users the ability to drill-through to underlying details [22]. Scorecards are often used for enterprise-wide monitoring of an organization's key performance indicators. Enterprise reporting BI tools allows reporting from across all areas of the enterprise and across multiple systems and platforms. These reports enable operational-level decision-making.

The Manchester Bidwell Corporation (MBC) is a social enterprise with locations around the world and is headquartered in Pittsburgh, Pa. MBC runs six programs designed to help teens and adults lift themselves out of poverty through job training programs and career placement. [13] MBC tracks and reports its ROI to the public; its student graduation rate for the past several years has been 76 percent and above. Even more remarkably, its job placement rate for its students (in the career for which they studied) is 80 percent. [13] MBC, and other job-training social enterprises, could benefit from the use of a data warehouse and BI tools to better track the resources used to attain those returns so that sound decisions about future programs could be made. The BI tools would capture KPIs related to financial and operational information as well as the KPIs, graduation rate and job placement, on a program-by-program basis.

If social enterprises like the $\mathrm{MBC}$ were to utilize data warehouses to collect all of their programmatic data as well as KPIs and financial indicators, it would not only help MBC make better investment decisions, it could be tied to other organizations working on similar social issues. In today's $21^{\text {st }}$ century global knowledge-based economy, it is simply no longer efficient for companies to maintain silos of organizational activity; in fact, it is a competitive handicap. [1, 19] Sharing data about the inputs, outputs, and outcomes would provide an easy to monitor BI scorecard - for individual social enterprises as well as a particular issue, like poverty, or target group, like the homeless.

However, the associations, individual social enterprises and entrepreneurs, funders, and the other players in the SE "ecosystem" need to come together to first build a data warehouse or digital library upon which any BI tools could rest. Robbins argues achieving that competitive advantage is not possible unless a company becomes a "learning organization," [19] or, an organization in which employees openly share what they know, working towards a shared organizational vision, through interrelationships between all functions, processes, and locations. IT plays a central role in facilitating all of these activities.

\section{Digital Libraries and the Case of the NSDL}

IT has certainly helped those interested in science by facilitating the creation of something similar to what the authors are proposing in this paper.

"Emerging distributed socio-technical infrastructures, as embodied by digital libraries, are transforming (and even disrupting) traditional work practices" [3]. However, "digital libraries need to be more than repositories and must support the full life cycle of data, information, and knowledge, and knowledge construction in general" [2]. This expanded view of digital library functionality "mandates an information model for DLs that is richer than a collection of simple web pages or static documents" [3] and further, that new information architectural models that 
embrace the concept of context of the object be created. "Context includes social and cultural information; patterns of use; pedagogical information, the nature of learners' educational systems; and the learner's abilities, preferences and prior knowledge." [3]

One such example of this "super-DL" is the National Science Digital Library (NSDL), which "provides high quality online educational resources for teaching and learning, with current emphasis on the sciences, technology, engineering, and mathematics (STEM) disciplines - both formal and informal, institutional and individual, in local, state, national, and international educational settings." [16] "The grand vision is that the NSDL become a comprehensive library of every digital resource that could conceivably be of value to any aspect of education in any branch of science and engineering, both defined very broadly." [25]

A key feature of the technical architecture of the NSDL is the "information network overlay" (INO). The INO is "the locus for modeling library resources, their descriptions, and the web of information that builds around them. [5] The access-controlled API lays on top of the INO and "provides full programmatic access to the INO". [5] The API can be "used by external contributors - e.g., the users, services, ontology classification services, and the like to enhance the information in the INO." [5] Figure 2 below shows the relationship between the various elements of the NSDL architecture. The primary resources layer contains data, organizations, documents, people, and services.

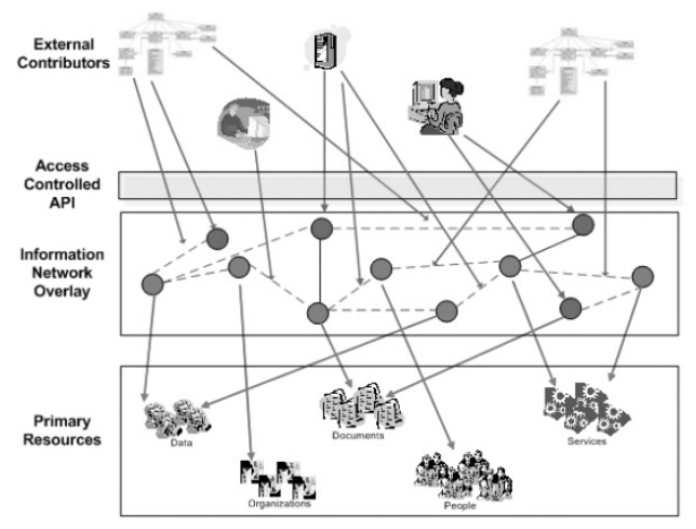

Figure 2 source: D-Lib magazine, http://www.dlib.org/dlib/november05/lag oze/11lagoze.html

\section{The Benefits}

The NSDL shows the benefit to stakeholders in a given subject area, in this case, science, coming together to create not just a digital library, but the ability to use it to learn, collaborate, and more: "In a library, be it digital or analog, the essential transaction is the same: a user interacts with content. But richer interaction is possible within the digital environment not only as more content is put within reach of the user, but also as more tools and services are put directly in the hands of the user. These include the ability to search, refer, validate, integrate, create, customize, publish, share, notify, and collaborate, to name but a few. Students, teachers, faculty, and those pursuing continuing education will 'connect to learn'; but they will also 'learn to connect', as they leverage their participation with other users of the library and its resources." [25]

The creation of a digital library (data warehouse) and BI tools for the social entrepreneurship community of practice would be a benefit to social entrepreneurs, academics, government agencies, funders, and corporations. Each of these stakeholder groups will gain something it needs and/or desires from the collaboration required to put together a consortium to execute on this project. 


\section{CONCLUSIONS}

Social enterprises, like their more traditional commercial counterparts, operate within an "ecosystem" of stakeholders, from the poor and hungry to the funders, government employees, charities, and others engaged in solving social issues. However, the ecosystem is much more complex and inherently visible in shaping the work and even the impact of the social enterprise than it is for traditional commercial enterprises. Issues such as poverty, hunger, and homelessness are too multi-faceted and complex for any one organization or sector to successfully address; however, the promise of social enterprises is in uniting all sectors to engage in addressing them. The associations that support social entrepreneurs have vast information, data, and knowledge stored in databases across the World that would greatly help this effort. We propose that social entrepreneurship associations form a knowledge coalition/partnership to explore the benefits and logistics of co-creating a data warehouse for the benefit of the world-wide community of practice.

\section{REFERENCES}

1. Aaker, D. A. (2008). Marketing in a Silo World: The New CMO Challenge. California Management Review, 51(1), 144-156.

2. Arms, W., Hillmann, D., Lagoze, C., Krafft, D., Marisa, R., Saylor, J., \& ... Van De Sompel, H. (2002). A spectrum of interoperability: The site for science prototype for the NSDL. D-Lib Magazine, $8(1), 15 \mathrm{p}$. doi:10.1045/january2002-arms

3. Austin, J., Stevenson, H., \& Wei-Skillern, J. (2006). Social and commercial entrepreneurship: same, different, or both? Entrepreneurship Theory and Practice, 30(1), 1-22.

4. Canes, M. (2009). Business intelligence for the SME. CA Magazine, 142(7), 46-48.

5. Cassel, L., Giersch, S., \& Recker, M. (2008). Educational digital libraries on the verge: introduction to the special issue. International Journal on Digital Libraries, 9(1), 1-2. doi:10.1007/s00799-008-0040-2

6. Chell, E., Nicolopoulou, K. \& Karatas-Ozkan, M. (2010). Social entrepreneurship and enterprise: International and innovation perspectives. Entrepreneurship \& Regional Development. Vol. 22, No. 6, pp. 485-493.

7. Dacin, P. A., Dacin, M., \& Matear, M. (2010). Social entrepreneurship: Why we don't need a new theory and how we move forward from here. Academy of Management Perspectives, 24(3), 37-57. doi:10.5465/AMP.2010.52842950

8. Gibson, C., Smythe, K. Nayowith, G. \& Zaff, J. (2013). To get to the good, you gotta dance with the wicked. Stanford Social Innovation Review. Accessed Sept. 24, 2013 on $\mathrm{http} / / / \mathrm{www} . \mathrm{ssireview} . \mathrm{org} / \mathrm{blog} / \mathrm{entry} / \mathrm{to}$ get_to_the_good_you_gotta_dance_with_the_wicked.

9. Inc, Z. D. (1999). PC Mag. Ziff Davis, Inc.

10. Kickul, J. \& Lyons, T. (2012). Understanding Social Entrepreneurship: The Relentless Pursuit of Mission in an Ever Changing World. New York: Routledge.

11. Langley, N. (2003). Find meaning in your data. Computer Weekly, 34.

12. Leviner, N.; Crutchfield, L. \& Wells, D. Understanding the Impact of Social Entrepreneurs: Ashoka's Answer to the Challenge of Measuring Effectiveness. Ashoka.org, n.d.

13. Manchesterbidwell.org

14. Mair, J. J., \& Martí, I. I. (2006). Social entrepreneurship research: A source of explanation, prediction, and delight. Journal of World Business, 41(1), 36-44. doi:10.1016/j.jwb.2005.09.002

15. Morse, E. A., Fowler, S. W., \& Lawrence, T. B. (2007). The Impact of Virtual Embeddedness on New Venture Survival: Overcoming the Liabilities of Newness. Entrepreneurship: Theory \& Practice, 31(2), 139-159. doi:10.1111/j.1540-6520.2007.00167.x

16. NSDL.org

17. PLOS.org/innovations

18. Reis, T. K., \& Clohesy, S. J. (2001). Unleashing new resources and entrepreneurship for the common good: A philanthropic renaissance. New Directions for Philanthropic Fundraising, 2001(32), 109-144. 


\section{Issues in Information Systems}

Volume 15, Issue I, pp. 353-359, 2014

19. Robbins, Stephen P. (2003). Organizational Behavior. Upper Saddle River, NJ: Pearson Education, Inc.

20. SEtoolbelt.org/

21. Smith, B. R., \& Stevens, C. E. (2010). Different types of social entrepreneurship: The role of geography and embeddedness on the measurement and scaling of social value. Entrepreneurship \& Regional Development, 22(6), 575-598. doi:10.1080/08985626.2010.488405

22. Turban, E. (2008). Business intelligence: A managerial approach. Upper Saddle River, N.J: Pearson Prentice Hall.

23. Wei-Skillern, J., Austin, J., Leonard, H. \& Stevenson, H. (2007) Entrepreneurship in the Social Sector. SAGE Publications: Los Angeles, CA.

24. Yunus, Muhammad. (2007). Creating a World without Poverty: Social Business and the Future of Capitalism. New York; Public Affairs.

25. Zia, L. L. (2001). Growing a national learning environments and resources network for science, mathematics, engineering, and technology education: Current issues and opportunities for the NSDL program. D-Lib Magazine, 7(3), 6p.. doi:10.1045/march2001-zia 